\title{
A (DES)CORTESIA NO BARROCO BRASILEIRO: EXPRESSÃO DE CULTURA
}

\section{Anderson Ferreira \\ Doutor em Língua Portuguesa pela Pontifícia Universidade Católica de São Paulo}

(PUC-SP)

andersonferreirasp94@gmail.com

Ricardo Celestino

Doutorando em Língua Portuguesa pela Pontifícia Universidade Católica de São Paulo

(PUC-SP)

Bolsista CAPES

ricardo.celestino2003@gmail.com

\section{RESUMO}

Em contribuição aos estudos enunciativodiscursivos pela perspectiva da Análise do Discurso de linha francesa, selecionamos a décima Outra pintura em sombras desta dama de Gregório de Matos Guerra, composta na segunda metade do século XVII, no período do Barroco brasileiro, e examinamos as estratégias de (des)cortesia nos enunciados que tematizam a beleza "de uma formosa dama". Nossa amostra de pesquisa consiste em um dos onze poemas do poeta dedicado a uma dama chamada Teresa. No desenvolvimento temático do discurso em análise, o enunciador funde erotismo e religiosidade, sacralidade e profanidade para retratar as qualidades de Teresa. Como aporte teóricometodológico, fundamentamo-nos na noção de cortesia proposta por Kerbrat-Orecchioni, pela qual ressignifica a teoria de Brown e Levinson, compreendendo a cortesia como a produção de antiameaças mediante os encadeamentos corteses e descorteses no desenvolvimento enunciativo. Consideramos, também, as contribuições do filósofo francês Gilles Deleuze, o qual discute, pela noção de dobra, os processos de construção de territórios existenciais do indivíduo dentro de sistemas de coerções e códigos múltiplos: a subjetivação. Ao estudar a subjetivação, Deleuze reflete não apenas acerca de um sujeito individual, mas de um modo intensivo de produzir a curvatura de certo tipo de forças sociais que, em nosso caso, influenciam na constituição do discurso selecionado e a maneira de apreender a (des)cortesia presente nos enunciados.

Palavras-chave: (des)cortesia, Gregório de Matos, dobra.

\begin{abstract}
In contribution with the French enunciative and discursive studies from the perspective of Discourse Analysis, we selected the poem Outra pintura em sombras desta dama by Gregorio de Matos Guerra, written in the second half of the seventeenth century, the period of Brazilian Baroque. We examined the strategies of (dis)courtesy in the statements that thematize the beauty of "a beautiful lady". Our survey sample consists of one of the eleven poems of the poet, dedicated to a lady called Teresa. In the thematic development of the discourse analysis, the enunciator fuses eroticism and religiosity, sacredness and profanity to portray the qualities of Teresa. As a theoretical-methodological approach, the paper is based on the notion of courteous behavior proposed by Kerbrat-Orecchioni which reframes the theory of Brown and Levinson, comprising courtesy as the production of antithreats by the courteous and discourteous in declarative development threads. We also consider the contributions of the French philosopher Gilles Deleuze, which discusses the notion of folding, the process of construction of existential territories of the individual within the constraints and multiple code systems: subjectivation. By studying subjectivation, Deleuze reflects not only about an individual subject, but an intensive way to produce the curvature of certain types of social forces that, in our case, influence the constitution of the selected discourse and the way of apprehending (dis)courtesy present in the statements.
\end{abstract}

Keywords: (dis)courtesy, Gregório de Matos, fold. 


\section{Considerações iniciais}

Em contribuição aos estudos enunciativo-discursivos propostos pela Análise do Discurso, doravante $A D$, temos como finalidade analisar as estratégias de (des)cortesia nos enunciados que tematizam a beleza no discurso Outra pintura em sombras desta dama, de Gregório de Matos Guerra. Composto na segunda metade do século XVII, no período do Barroco brasileiro, a obra consiste em onze poemas de Gregório de Matos dedicado a uma dama chamada Teresa. Os enunciados, para retratar as qualidades de Teresa, fundem erotismo e religiosidade, sacralidade e profanidade, moralidade e questões étnico-raciais.

Selecionamos como aporte teórico-metodológico a noção de (des)cortesia proposta por Kerbrat-Orecchioni, a qual ressignifica a teoria de Brown e Levinson, compreendendo a (des)cortesia como a produção de antiameaças mediante os encadeamentos corteses e descorteses no desenvolvimento enunciativo. Identificamos que a engenhosidade da estética barroca implica, como um de seus traços profundos, estimular a ambiguidade de semas socialmente (des)corteses, em nosso caso, aqueles cujo campo semântico é a negritude.

Consideramos, também, as contribuições do filósofo francês Gilles Deleuze, o qual discute, pela noção de dobra, os processos de construção de territórios existenciais do indivíduo dentro de sistemas de coerções e códigos múltiplos: a subjetivação. O que nos interessa no estudo sobre a subjetivação não é a presença de um sujeito individual no discurso selecionado, mas um modo intensivo de produzir a curvatura de forças sociais que influenciam na constituição de Teresa e acarretam na maneira de apreender a (des)cortesia presente nos enunciados. 


\section{O Barroco e o não-lugar artístico}

Gregório de Matos Guerra nasceu na cidade de Salvador, em 1636. Pertencente à elite brasileira, seu pai possuía fazendas na Bahia e um canavial em Patatiba que contavam com 130 escravos de serviço. Terceiro de três irmãos de destaque na época, demonstra, já em sua juventude, predisposição à caricatura verbal e anedotas jocosas e picarescas. Doutor em Leis, formado em Coimbra, Gregório de Matos alterna a vida boêmia com o estudo formal em Portugal.

Rabelo (1929) afirma que, durante duas décadas de vida, o poeta atuou na área de advocacia em Lisboa, onde criou fama de causídico adestrado e ladino. Dada sua aproximação com D. Pedro II, príncipe regente de Portugal, tornou-se evidente na Corte e passou a executar funções diretas à nobreza portuguesa. Um dos episódios que marcou o destino de Gregório de Matos, em Portugal, fora a sua rejeição na execução de uma delação de crimes praticados por Salvador Correia Benevides, a mando da Corte Portuguesa. O motivo da negação em executar o serviço é incerto. Uns dizem que o poeta temeu as represálias de Benevides, outros afirmam que, por ter recebido ordenado antecipado, fiou o caso. O que se evidencia, contudo, é a insatisfação do poeta pelo papel de delator e espião do Príncipe Regente.

Em Portugal, desenvolveu poucas sátiras sobre os amores que tivera, o que the despertou o talento para a arte. No entanto, suas produções ainda eram tímidas comparadas às do Brasil. Rabelo (1929) revela que Matos encontrou em uma pequena cidade da Bahia material para o aprimoramento de sua análise social. Cidade de forte mistura étnico-racial, encontrava-se em convivência brancos, que correspondiam à elite, índios, escravos negros, mulatos e ciganos, os quais representavam o braço servil. A Bahia 
seiscentista tinha sob principal influência moral e ética a antítese entre a educação jesuítica e a vida desregrada das festas religiosas e pagãs. Aflorava-se, ainda, a sexualidade grupal e pecadora aos modos cristãos, que marcava o misto de civilização e barbárie.

A desunião entre classes sociais, as intrigas, aleivosias e arbitrariedades, as desigualdades entre a elite e as camadas mais pobres acentuam, aos olhos de Gregório de Matos, uma luta entre sua poesia e seu meio. O poeta, conforme Rabelo (1929), é tomado por um sentimento de solidão diante de uma cidade em formação e assume como sua principal arma a sátira de ponta aguçada e venenosa. O discurso que nos propomos analisar neste artigo insere-se nessa fase de vida do autor.

A obra poética de Gregório de Matos tem como referencial a cartilha de Luis Gôngora (1561-1627), Franscico de Quevedo y Villegas (1580-1645) e Lope de Vega (1562-1635) inserindo-se na estética barroca. Para refletirmos sobre a arte Barroca e a expressão que ela implica na Literatura seiscentista, é imprescindível retomarmos aspectos do Renascimento e da Idade Média. Compreendemos que o discurso literário seiscentista é uma manifestação do ser frente às questões mundanas, institucionais e filosóficas.

No Barroco, há uma tragicidade lúdica das expressões do eu. Como afirma Neves (1986), a arte barroca desloca-se do mundo e o transcende, uma vez que sobrepõe às leis absolutas e anônimas, e os artistas forjam uma realidade transcendente a elas. O Barroco difere-se, assim, do racionalismo matemático da Renascença e do individualismo Iluminista, operando na contradição das conformações ideais que regiam as instituições sociais seiscentistas. Há, deste modo, a inauguração de uma nova postura à racionalidade, ofertada pelo Barroco, advinda de uma causalidade que contém as 
mudanças do enfoque da razão. Trata-se, então, de uma nova concepção de mundo, de arte e de razão.

A razão nada mais é do que uma autocompreensão do ser humano por ele mesmo e de suas experiências, como enfatiza Ladrière (1979). O sentido racional das coisas só é claro no e pelo discurso e funciona como uma mobilização de posicionamentos daquele que enuncia àquele que coenuncia o discurso. Para este autor, no Barroco, há uma polêmica em torno do que é racional, sendo a razão a defesa de um ponto de vista. Neste particular, a clareza acessível é aquela que o discurso revela, limitada pelos sentidos possíveis do discurso. Não há, então, expressão nem sentidos absolutos, mas a composição de simulacros racionais.

O Barroco surge, portanto, como o movimento que transgride a razão absoluta, pois propõe um jogo das relações instituidoras de sentido. Ele reflete o que há de mais radical no campo da experiência e busca a anticompreensão do ser humano que não se inscreve em uma lógica racional. A compreensão das relações entre pensamento e extensão não é um tema central no Barroco, como argumenta Neves (1986), mas busca-se a captação das regiões claras de sentidos e conteúdos explícitos e do saber silencioso. A razão é fruto do que não é razão, mas ainda é realidade humana.

Neves (1986) enfatiza a existência de uma revolta transgressora do Barroco, manifestada pelo eu que busca reinstalar-se como centro, em contradição ao eu que transcende o racionalismo iluminista. Há um saber silencioso circulante e constituinte do discurso barroco o qual trata o eu sobre ele mesmo e o eu banhado de mundo. Deste modo, o Barroco distancia-se da acepção de cogito de Descartes (1596-1650), já que as configurações do Barroco expressam uma realidade escondida que transcende o 
enunciado e sua pretensão de verdade. Há, portanto, uma verdade desejosa de vir às claras e uma recusa do microespaço do discurso lógico.

Ladrière (1979) propõe visualizar o Barroco sob a luz de duas figuras teóricas, que ilustram bem o que é o pensamento barroco. De um lado, recupera as teorias de Marx (1818-1883), que pensa a sociedade tal como a vemos e como ela se exprime nas leis, nos princípios, dentre outros. Trata-se de uma manifestação aparente de uma realidade escondida. De outro lado, há um sonho social, fruto de uma vida social explícita, como a vemos enquanto produtores, cidadãos, pensadores. Em outras palavras, um sentido escondido do sonho que se esclarece na análise e que não se exprime nas instituições.

Em face às duas figuras teóricas propostas por Ladrière (1979), compreendemos que o Barroco pressupõe uma tragicidade elementar que irá reger a estruturação de seu discurso, como modalidade de cognição. O discurso barroco não traduz apenas uma estrutura mental de sua época, mas também imprime o próprio modelo mental. Assim, não é a causa ou efeito de uma modalidade racional, mas uma dentre tantas possibilidades de expressão, face ao dinamismo cultural do período. Em nosso caso, ao estudarmos Gregório de Matos, temos um dinamismo em que destacamos os campos religioso e artístico, que servem de filtro para observar realidades dentro de um mesmo discurso.

As imagens ou os discursos apresentados pelo Barroco são sedutores por si só. Neves (1986) compreende a sedução como um laço emotivo que se realiza face à interação discursiva. Isso significa que não há uma doutrina por dedução ou indução, mas um princípio pela emoção. Dessa forma, o discurso barroco é um fenômeno do jogo emotivo. Neves acredita que há um vai e vem do jogo que simboliza um movimento de engenhosidade, o qual propõe semas cujos sentidos seguem fluxos muitas vezes 
imprevisíveis. Dito de outro modo, há uma estratégia de sedução, pautada nos mitos sociais que oferecem subsídio para a constituição do papel de um enunciador que seduz o coenunciador. O jogo sedutor é o que fundamenta o discurso como transgressor em seu tempo. A guisa de exemplo, recuperamos padre Antonio Vieira e Gregório de Matos, punidos em sua época, pelos posicionamentos religioso e literário, respectivamente; e frei António das Chagas que durante um bom tempo foi conhecido como o fradinho, tanto por sua proximidade aos fiéis, quanto por seu valor menor na prática religiosa.

Nessa senda, entende-se jogo sedutor como a autoridade sedutora da imagem diante da própria sedução ou emoção, conforme enfatiza Neves (1986). Com efeito, trata-se de um jogo de transgressão dos cânones vigentes. No Barroco, há uma transgressão ao cânone racionalista. Ao transgredir a vontade canônica, não há vida para aquele discurso, mas morte e negação social. Desse modo, o Barroco escapa do preconceito hegeliano que se baseia em intuir uma razão conceitual aos discursos produzidos. O Barroco foge a qualquer tipologia; é a arte de autorreflexão, já que contém uma consciência de si mesmo.

O Barroco, contudo, não inventa subversões, mas media realidades por meio de uma angulação subversiva de filtrar o mundo. Encontra-se no entremeio do cânone e da decadência, constituindo-se o cânone. É, em última instância, um movimento que subverte o Outro, cujo pressuposto prescreve a canonização do subversivo para se tornar cânone. O Barroco, por fim, é a historicidade do discurso revoltado do homem diante do colapso das instituições sociais.

Na compreensão de Neves (1986), a subversão ocorre como uma lógica que gira em torno da crítica sobre a maneira de fazer e o que se faz. Vincula-se a cânones anteriores, mas contém a revolta que inaugura uma luz moderna. Não há, no discurso subversivo, 
uma substituição de um paradigma por outro, mas a apresentação de que aquilo que se faz depende da maneira de fazer. Neves, então, recupera Eco (1999), para embasar uma reflexão fulcral: para se compreender a arte é necessário compreender toda a poética que a sustenta e a embasa.

Portanto, o jogo barroco é uma transgressão vigiada e consentida. Há a transgressão do cânone, sabendo os limites aonde se pode chegar. O artista barroco busca os canônicos medievais para transgredir a Renascença. A arte barroca se instala no campo da representação e possui uma estética que é repensada o tempo todo. Podemos compreender o Barroco como um movimento tributário de um cânone, ao mesmo tempo em que sua forma escapa a qualquer cânone vigente.

\section{2. (Des)cortesia e a dobra}

Enunciar sobre manifestação (des)cortês em um discurso é depreender acerca de enunciados que garantem certo efeito de sentido, a partir da interação entre enunciador e coenunciador. Orecchioni (1994) parte do pressuposto que a cortesia é uma negociação entre os envolvidos na enunciação, o que pressupõe refletir a prática enunciativa suscetível ao contrato, ao jogo e às regras propostos pelo gênero de discurso'. A partir de um agenciamento de imagens do enunciador e dos efeitos de sentido construídos pelo coenunciador, a cortesia é submetida aos limites do gênero e do tipo de discurso.

A cortesia, para Orecchioni (1994), pressupõe a construção de espaços de antiameaça no ato enunciativo. Trata-se de enunciados encadeados com outros enunciados que têm como pressuposto garantir a polidez do discurso. Podem ser observados como recurso positivo no sentido de estar contrário do enunciado natural. Ao 
efetuar qualquer ato de antiameaça, o enunciador valoriza a face positiva e implica a negativa do coenunciador, já que recupera atos valorizadores da imagem do outro e omite elementos desvalorizadores.

Os intercâmbios de cortesia, que acometem uma enunciação, na compreensão de Orecchioni (1994), constituem duas partes, a saber: encadeamentos preferidos e encadeamentos descorteses. Encadeamentos preferidos de enunciados corteses são aqueles que englobam um acordo, uma petição, uma acepção, uma autocrítica ou um desacordo na interação enunciativa. Os encadeamentos descorteses são enunciados que refutam ou negam determinado posicionamento ou crença de um coenunciador. A autora observa a relação interpessoal organizada sobre três eixos ou variáveis: relação horizontal e relação vertical, as quais pressupõem o domínio de um sistema de lugares; e a relação afetiva, que expressa um conflito ou um consenso.

A autora distingue ainda a cortesia positiva da cortesia negativa, as quais clarificam o modelo e a concepção pessimista ou otimista da cortesia. A divisão proposta por Orecchioni é de natureza sociológica, no entanto permite a relação linguística com o social. Vislumbra-se, deste modo, uma relação fundamental para o estudo da cortesia, no que tange ao uso das formas de tratamento, das dimensões de solidariedade e distância.

Compreendemos que a função reguladora da cortesia está ligada ao funcionamento social do gênero. No caso de nosso corpus, trata-se de um gênero de discurso poema, que, em suas condições sócio-históricas de produção, fora utilizado pelo poeta Gregório de Matos para caricaturar a sociedade baiana de sua época. O gênero, assim, impõe constrições à relação interpessoal e cortês. A cortesia, quando verbal, pressupõe uma competência sociocultural e linguística específica do gênero de discurso. Há formas de tratamento que são próprias de um gênero e instituídas por ele. Contudo, quando a 
cortesia é uma escolha do enunciador, passa a ser utilizada como uso estratégico com a finalidade de provocar um efeito de sentido específico. Embora seja uma categoria pensada por Orecchioni (1994) a partir de interações verbais ordinárias, nada nos impossibilita de estudá-la na prática enunciativo-discursiva de um poema, como veremos adiante em nossa análise.

Entendemos que a construção de lugares (des)corteses em um discurso literário é fruto dos processos de subjetivação que envolvem o ato enunciativo. Dessa maneira, mobilizamos os estudos de Deleuze (1991) que, ao discutir a noção de dobra, reflete acerca de processos de construção de territórios existenciais do indivíduo dentro de sistemas de coerções e códigos múltiplos. O filósofo francês define esses processos como a subjetivação e defende a ideia de que se trata de um modo intensivo de produzir ou tornar externa a curvatura de certo tipo de forças sociais. Ao tomarmos a linguagem como prática enunciativo-discursiva, identificamos que as reflexões sobre dobra podem contribuir, de modo significativo, na problematização acerca da constituição dos enunciados de nossa amostra de pesquisa e, ainda, na maneira de apreender a (des)cortesia presente nos enunciados.

Deleuze (1991) compreende dobra como um conceito da filosofia que apresenta uma ferramenta teórica para refletir a experiência subjetiva contemporânea. Trata-se de um território subjetivo em processo de construção o tempo inteiro, que exprime uma coextensão do dentro e do fora. Em uma formação histórica específica, a dobra nos oferece a compreensão dos processos de construção de territórios existenciais do indivíduo, definido por Deleuze (1991) como a subjetivação. A ideia de indivíduo traduz certa captura da subjetividade dentro de um determinado sistema de códigos, em nosso caso, o seiscentismo que marca a dualidade sacro-profana do Barroco brasileiro. 
Cada formação histórica irá dobrar de forma diversa a composição de forças que a atravessa, dando-lhe um sentido particular. De fato, a noção de dobra, proposta por Deleuze (1991), é bastante produtiva para a compreensão da subjetivação em uma dimensão interdiscursivaii. Vale-se do ponto conceitual para observar a produção discursiva ao longo da história, a partir das diferentes relações possíveis entre o indivíduo e o mundo. Deleuze, desse modo, propõe uma definição de dobra ao questionar o conceito de pensar da filosofia cartesiana e propõe o ato de pensar como constitutivo da interação entre dois planos: o plano de imanência e o fora.

O plano de imanência consiste na reflexão de que o solo onde se tece a imagem que o pensamento faculta do que significa pensar detém rastros de inconsciência social. Seria, em outras palavras, o impensado no pensamento, ou um deserto movente que os conceitos vêm povoar. Os conceitos, ou personagens conceituais, designam uma presença intrínseca ao pensamento, uma condição de possibilidade do próprio pensamento.

A partir dessa reflexão, Deleuze (1991) argumenta que a dobra introduz uma diferença fundamental, desde Descartes, do que significa pensar para a Filosofia. Descartes compreende que o pensamento não remete ao próprio pensamento, mas a pressupostos implícitos e subjetivos calcados na forma pessoal e individual de um sujeito. Deleuze (1991), por sua vez, argumenta que pensar não é um exercício natural de uma faculdade. Só pensamos quando algo nos força a pensar. Isso quer dizer que o pensamento não é um ato involuntário, como se revela na filosofia cartesiana, mas tem relação imediata com o fora, compreendido como um campo intensivo que se desloca de maneira interna e externa ao indivíduo. O fora, para Deleuze (1991), é uma máquina abstrata que emite singularidades e envolve o movimento infinito do pensamento. $\mathrm{O}$ 
plano da imanência é como uma espécie de topologia traçada a partir de emissões singulares de pensamento sobre o fora. Pensar, para Deleuze, é uma potência de invenção dentro de um sistema de coerções dados, o qual chamamos de universo de formações discursivas que constituem uma época.

O ato de pensar, segundo o filósofo, está intimamente relacionado com a construção de sentidos em um discurso. Para Maingueneau (2008), o sentido não percorre dos enunciados para o interior do coenunciador, mas atua de forma polêmica, e se é validado na prática enunciativa é porque aquilo que foi enunciado está de acordo com um sistema de formações discursivas daquele que coenunciou o discurso. Se levarmos em consideração a noção de dobra, ao refletirmos construções enunciativas que nos remetem a efeitos de sentido de cortesia, identificamos a possibilidade de um desentendimento mútuo em um mesmo enunciado, que nos leva a depreendê-lo, ao mesmo tempo, (des)cortês.

\section{A (des)cortesia de Gregório de Matos}

Gregório de Matos realiza, em seus poemas compostos na Bahia, uma literatura nacional sob o aspecto social, todavia sob uma estética influenciada por Gôngora e Quevedo, como já dissemos. O autor foca na análise da paisagem humana do Brasil colonial, de modo específico, na Bahia. E podemos tomá-lo como um cronista do viver baiano seiscentista. Apropriando-se da sátira burlesca, crua e desabusada, reflete os costumes do clero, dos colonos portugueses, dos brasileiros amulatados, dos descendentes de índios, dos ricos, dos pobres e dos desvalidos. 
Selecionamos, como amostra para este artigo, a décima Outra pintura em sombras desta dama, a qual consiste em um dos onze discursos produzidos pelo autor, dedicado a uma dama chamada Teresa. Identificamos que, na prática enunciativa, há a fusão do erotismo e da religiosidade, da sacralidade e da profanidade, fundamentais para retratar as qualidades de Teresa. As estratégias que tematizam a beleza de Teresa possibilitam reflexões sobre a relação de (des)cortesia que o enunciador estabelece com quem ele se propõe enunciar, como podemos observar na décima abaixo. Numeramos as estrofes para melhor identificarmos os enunciados na análise.

[1] Seres formosa, Teresa, sendo trigueira, me espanta, pois tendo beleza tanta, é sobre isso milagrosa: como não será espantosa, se $o$ adágio me assegura, que, quem quiser formosura, a há de ir na alvura ver, e vós sois linda mulher contra o adágio da alvura.

[2] Mas o nosso adágio mente, e eu the acho a repugnância, de que a beleza é substância, e a alvura é acidente: se na esfera tão luzente dessa cara prazenteira o sol como por vidreira se duplica retratado, sendo vós sol duplicado, que importa seres trigueira.
[3] Eu melhor coisa não vi de olhos, do que vossos olhos, no ferir almas abrolhos, no caçar almas nebli: cos vossos olhos aqui me sinto tão arriscado, que me dá menos cuidado, e fora a melhor partido dos vossos olhos mordido, que da vossa vista olhado.

[4] Se todo o mundo pisara, não vira no mundo inteiro nem riso mais feiticeiro, nem mais agradável cara: tinha-vos por coisa rara, notável, e prodigiosa; mas acho, que artificiosa em vós natureza obrou pois sobre sombras pintou uma cara tão formosa.

A cortesia, como expediente de preservação e valorização da imagem dos coenunciadores, revela-se em primeiro plano, sendo um fio condutor do cortejo do enunciador a uma dama chamada Teresa. Notemos que há um tratamento (des)cortês num plano global do discurso, em que o fio condutor é a cortesia como valorização da imagem de Teresa. Acreditamos ser cortês, pois o enunciador destaca somente bons 
atributos sobre Teresa. Contudo, podemos tomar o discurso também como descortês, uma vez que os atributos destacados pelo enunciador se restringem aos campos semânticos da sexualidade, seres formosa, Teresa, e linda mulher contra o adágio da alvura. Para Teresa, seus atributos que a qualificariam, também é alvo de desqualificação de si e de quem com ela interagir.

Deste fio, desfia-se também um outro pelo qual observamos a sátira aos costumes e às tradições seiscentistas. A abordagem (des)cortês do enunciador pode ser evidenciada pela relação interdiscursiva com o discurso da religiosidade.

Nos enunciados seres formosa, Teresa / sendo trigueira, me espanta, / pois tendo beleza tanta, / é sobre isso milagrosa [1], o enunciador estabelece um jogo que permite o desdobramento com formações discursivas no que se refere à desvalorização étnicoracial e à permissão de exaltar a beleza, estatutos instituídos no Brasil seiscentista. Teresa é apresentada como trigueira, ou seja, de cor escura, morena ou negra. A beleza de Teresa é alvo de espanto pelo enunciador, justamente devido a sua cor. A cor da pele define o sujeito na sociedade seiscentista, bem como seus direitos de acesso a determinados grupos institucionais.

Quando o enunciador revela ser um erro ou um espanto tematizar a beleza de uma mulher de cor em uma décima, haja vista a justificativa enunciada: sendo trigueira, me espanta / pois tendo beleza tanta, / é sobre isso milagrosa [1], notamos instaurar-se nos enunciados destacados um jogo típico do cultismo barroco, fruto do desdobramento de sentidos que os enunciados proporcionam, que nos leva a questionar: trata-se de um milagre o desvelar da beleza em uma mulher negra, ou o milagre consiste em enunciar a beleza de uma mulher negra? 
A construção de uma Teresa trigueira - mestiça, sensual e formosa - tem como escopo desconstruir a Teresa europeia, não só pelo aspecto da "civilidade", mas também por ser a mulher branca a preferida dos escritores da sociedade da época, a qual reverbera sua opinião, consoante o enunciador, pela repetição de um adágio. Poderíamos entender este adágio como metáfora do senso-comum, uma sabedoria popular que vem sendo repetida por anos de forma a se cristalizar. Neste caso, o enunciador acusa a sabedoria popular de mentirosa e repugnante por somente ver na alvura, ou na mulher branca, a beleza.

Em [...] como não será espantosa, / se o adágio me assegura, / que, quem quiser formosura, / a há de ir na alvura ver, / e vós sois linda mulher / contra o adágio da alvura [1], evidencia-se um dos efeitos de sentido possíveis do discurso que nos direciona a refletir sobre a (des)cortesia construída pelo enunciador em seu discurso: problematizar a questão étnico-racial. Para o enunciador, o adágio determina que apenas é formosa aquela que se integra ao adágio da alvura. Identificamos a possibilidade de desdobrar o adágio como um sistema de crenças populares de teor moral, que, quando adjetivado com alvura, ou seja, daquilo que é muito alvo, ou branco, suscita-nos a condição de imoralidade de uma mulher que foge dos padrões morais instituídos na época, ou a própria questão da cor da pele que é condição para marginalização social.

O enunciador afirma que a beleza de Teresa resume-se a uma oposição ao adágio da alvura. Podemos desdobrar, deste modo, efeitos de sentido que mobilizam a figura de Teresa como a representação de mulheres negras que, só pelo fato de existirem e circularem nos lugares sociais possíveis no século XVII, são tomadas como descorteses perante o adágio da alvura. Contrapartida é o enunciador considerar, frente a essa memória social, que não há descortesia da dama frente à sociedade, mas da sociedade 
frente à mulher negra, já que há projeção de uma beleza repreendida, que urgencia ser velada por uma sociedade que ri de forma feiticeira. A (des)cortesia, dessa maneira, encontra-se na inter-relação entre Teresa e a sociedade em questão.

Outra manifestação de (des)cortesia encontrada na enunciação está na falta de afinação entre o enunciador e o meio em que vive. $O$ enunciador projeta-se como um sujeito que tende a aproximar a questão étnico-racial com a sensualidade e fundir erotismo e religiosidade. Dessa forma, o enunciador instaura um embate entre o sacro e o profano. Além de ser milagrosa por ser trigueira, Teresa tem o olhar evidenciado pelo enunciador. Todavia, longe de um olhar que anuncia um amor puro e contemplativo, Teresa tem um olhar caçador. Seria produtivo lembrar aqui o discurso religioso de Santa Teresa de Ávila o qual versa sobre o prazer terreno e o amor místico. É nesse jogo místico da caça e do caçador que a Santa se torna a caça e depois aprisiona o Senhor tornando-se caçadora, como observamos no discurso teresiano: "Quando o doce caçador / Me atingiu com sua seta / Nos meigos braços do Amor / Minh' alma aninhou-se quieta" (SANTA TERESA, 2001, p. 969).

Esta interação é retomada pelo enunciador de nossa amostra. O olhar não é somente sedutor, mas, sobretudo, caça e fere seus pretendentes. [...] Eu melhor coisa não vi / de olhos, do que vossos olhos, / no ferir almas abrolhos, / no caçar almas nebli: / cos vossos olhos aqui/me sinto tão arriscado, / que me dá menos cuidado, / e fora a melhor partido / dos vossos olhos mordido / que da vossa vista olhado [3]. Erotismo e religiosidade fundem-se neste ponto com a retomada do pensamento religioso do discurso teresiano com a construção de uma Teresa sensual, sedutora e formosa.

Há de se notar, ainda, uma tentativa de desconstruir aquilo que a tradição impôs por meio do pensamento aristotélico: a ideia de essência, substância e acidente. Teresa é 
a essência e sua substância é a beleza, sendo que a alvura é acidente que, como característica secundária, apenas modifica a substância, mas não altera sua essência. [...] Mas o nosso adágio mente, / e eu Ihe acho a repugnância, / de que a beleza é substância / e a alvura é acidente. [2]. Essas desconstruções podem ser tratadas no sistema de cortesia de Kebrat-Orecchioni (1996) como princípios orientados, de acordo com os quadros abaixo que retiramos de Rodrigues (2000, p. 4):

\section{Quadro1}

\section{(I) Princípios A-orientados}

(1) Cortesia negativa:

Evite ou atenue atos verbais ameaçadores para

a) a face negativa do alocutário

(2) Cortesia positiva:

Produza atos verbais valorizadores de

a) a face negativa do alocutário

b) a face positiva do alocutário.

Princípios A.

\section{Quadro 2}

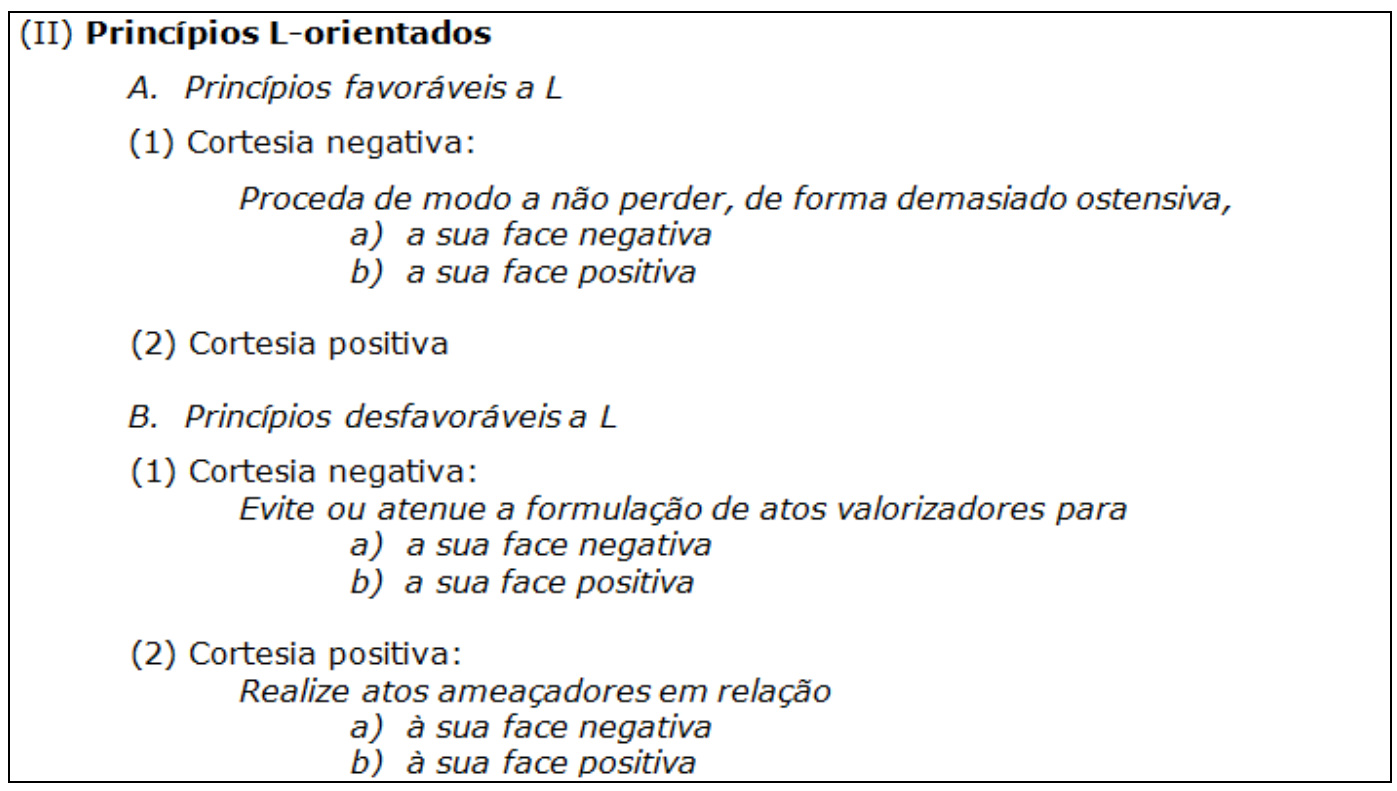

Princípios L. 
Na perspectiva interacionista, A (alocutário) e L (locutor) interagem no ato da interação verbal, visando a um destinatário. Todavia, a noção de destinatário não é de fácil manejo, ele pode ser, nesse caso, tanto a quem o locutor se dirige diretamente (alocutário), como a quem está "fora" da interação. Em uma perspectiva enunciativodiscursiva, dizemos enunciador para diferenciá-lo do locutor, já que aquele responde não só a um enunciado, como também a um conjunto de textos ou sua dispersão. Portanto, o enunciador no discurso de Gregório de Matos está ligado ao gênero do discurso em suas condições sócio-históricas de produção numa relação híbrida do sujeito empírico-crítico de sua sociedade, do poeta-sujeito oriundo de formações discursivas e do autor- instância autoral.

Deste modo, a face positiva ou negativa do enunciador será destacada nas relações interdiscursivas e na função reguladora que a cortesia possui do contexto. 0 coenunciador, por sua vez, não pode ser entendido, em nossa análise, como destinatário ou alocutário, mas como aquele que se comunica com o discurso em questão. Nesta comunicação, ao fundir-se erotismo e religiosidade, funde-se, também, o sagrado e o profano. A expectativa disposta no Quadro 1 é quebrada.

O coenunciador, sócio-historicamente situado, tem produzido contra sua face enunciados ameaçadores - cortesia positiva - tanto no campo do discurso religioso, como no campo do discurso erótico. Ao mesmo tempo, o enunciador produz enunciados que valorizam tanto a face positiva, quanto a face negativa do coenunciador, estes enunciados se constituem no campo do discurso étnico-racial.

Este é o jogo paradoxal que o Barroco institui. Se conjecturarmos que os leitores de poemas no século XVII eram, de modo majoritário, uma elite rica e branca e, em sua maioria, cristãos, podemos propor que, neste caso, como exposto no Quadro 1, a cortesia 
negativa e positiva atuam como forças de contraste. Embora o enunciador apresente certo engajamento com a sociedade de sua época, ele critica os conhecimentos legitimados, desconstruindo, de modo simbólico, a figura de Santa Teresa e, igualmente, o conceito de beleza, o qual se apropria do discurso aristotélico. Revela-se, no e pelo discurso, ainda certa desconfiança em relação ao mestiço no que diz respeito à beleza. Seres formosa, Teresa, / sendo trigueira, me espanta. [1]

Tal desconfiança funciona como cortesia positiva em relação à face do coenunciador sócio-historicamente situado, pois este, mesmo em embate com uma Teresa aproximada a uma Santa sensual, relaciona a questão étnico-racial, naquela sociedade, à condição erótica. [...] pois tendo beleza tanta, / é sobre isso milagrosa [1]; [...] sendo vós sol duplicado,/que importa seres trigueira. [2]. Ou ainda [...] tinha-vos por coisa rara, / notável, e prodigiosa; / mas acho, que artificiosa / em vós natureza obrou / pois sobre sombras pintou / uma cara tão formosa [4]. Em outras palavras, ao mesmo tempo em que o enunciador elogia a beleza de Teresa, considera notável essa beleza advir de uma mulher mestiça. A natureza, deste modo, realizou uma grande obra: pintou, mesmo por cima da pele escura de Teresa, uma cara tão formosa, digna da alvura.

No Quadro 2, podemos observar os Princípios - A favoráveis e desfavoráveis à face do enunciador. Nos Princípios favoráveis à cortesia negativa, o locutor L é orientado a não perder, de forma muito evidente, a sua face negativa e a sua face positiva. Nesse sentido, entendemos que deve haver um equilíbrio no momento da interação. No discurso em análise, esse equilíbrio torna-se incompatível pelas próprias condições de criação do Barroco, sobretudo, pelo conceito de dobra proposto por Deleuze (1991). É condição do discurso artístico seiscentista o empenho estético engenhoso, que desdobre diversos campos discursivos a fim de constituir uma razão que se manifeste e funcione apenas 
como verdade provisória no discurso. Trata-se da noção de cultismo e conceptismo propostos pelos manuais de retórica da época, que diferenciam o bom e o mal artista, mediante sua desenvoltura em desdobrar sentidos com as múltiplas verdades instituídas na sociedade.

A noção de verdade se esvai à medida que se multiplica os efeitos de sentido possíveis de cada verso enunciado no discurso artístico. 0 enunciador propõe enunciados que permitem o choque de posicionamentos, o qual tomamos como (des)cortês à moralidade social da época. Nos enunciados [...] mas acho, que artificiosa / em vós natureza obrou / pois sobre sombras pintou / uma cara tão formosa [4]; o enunciador retrata a sombra como a cor da pele de Teresa, sua representação social marginal ou a maneira como se comporta dissonante de sua beleza. Todos esses efeitos de sentido podem representar Teresa em sua complexidade, da pureza à erotização de sua beleza.

Dessa forma, o enunciador revela sua face negativa ao fundir, em seu discurso, a religiosidade, aludida na figura de Santa Teresa e o erotismo, ao propor uma Teresa sensualizada. O enunciador, neste caso, fala do lugar do profano, tal que este discurso não pode se erigir sem trazer consigo o discurso do sagrado. Todavia, sua face positiva é revelada, diante das condições sócio-históricas de produção do discurso, pelo fato de explicar a beleza de Teresa pelo campo religioso que mobiliza o item lexical milagrosa, em confronto com o campo místico que mobiliza o item lexical feiticeira. Trata-se, portanto, de aproximar a beleza ao milagre e a ordem do sagrado e, ao mesmo tempo, aproximar a beleza de Teresa ao feitiço, ou seja, do latim facticius (artificial, não natural). Em última instância, visa-se a aproximar Teresa ao profano.

Há de se observar que, para leitores atuais, a face positiva do enunciador na cortesia negativa pode ser relativizada. Ademais, pode-se acrescentar que o discurso 
contém um paradoxo, comum ao Barraco: o fato de retomar o pensamento aristotélico, ou melhor, recorrer à realidade sensível para explicar a beleza, ao mesmo tempo em que se atribui essa beleza a um milagre da natureza, já que Teresa é mestiça, sendo, pois, seu sorriso um feitiço.

De outro modo, a cortesia positiva é controlada pelo gênero do discurso, no caso um poema. Gregório de Matos usa uma forma poética chamada décima muito usada para satirizar. Ao ser recebido como sátira, o discurso pode deslegitimar tanto os elogios que o enunciador tece a Teresa, como uma crítica contundente à sociedade de sua época. Contudo, ao ser recebido como discurso de expressão de uma cultura, o discurso reconstrói um lugar malogrado que desdenha os antigos modelos para por à luz outro mundo.

Ainda no Quadro 2, os Princípios desfavoráveis - L, em relação à cortesia negativa, orienta o locutor a evitar ou a atenuar a formulação de atos valorizadores para sua face negativa e sua face positiva. $O$ enunciador valoriza sua face negativa em relação a Teresa num ato cortês em detrimento àquela sociedade que rejeita a beleza advinda da mestiçagem. Mas evita atos valorizados à sua face positiva em relação à sociedade, embora faça uma crítica a ela. Da mesma forma, na cortesia positiva, os atos ameaçadores à sua face são realizados diante das condições sócio-históricas do discurso em análise, isto é, o enunciador no quadro de desconstrução de modelos é tomado por descortês.

\section{Considerações finais}


O discurso analisado preenche uma lacuna do cotidiano seiscentista brasileiro. Identificamos que o enunciador serve-se das formações discursivas que constituem os ritos sociais de seu entorno, para construir sua arte engenhosa. A arte de Gregório de Matos é multifacetada - o esperado pelos grandes cultores da época - e permite uma prática leitora que transcenda a precisão de efeitos de sentido. A noção de (des)cortesia proposta por Orecchioni (1996), somado ao conceito de dobra, proposto na filosofia pósestruturalista de Deleuze (1991), nos permite observar o discurso como lugar de produção e criação de efeitos de sentido, em que cada possibilidade de leitura depende das formações discursivas que constituem o coenunciador enquanto sujeito-social e a maneira como ele desdobra essas formações para gerar sentido.

O tráfego entre os campos do sagrado e do erótico, da moralidade e étnico-racial, definem o cenário para entendermos a complexidade da sociedade seiscentista e o eco dessas culturas na atualidade. O discurso analisado estimula a observação da sociedade não como definições cartesianas de certo e errado, mas como um rizoma o qual cada ramificação de sentido que se abre é tão legítima quanto a outra. Evidencia-se, ao término dessa análise, que não existe um tronco principal que define o certo e o errado sob a beleza de Teresa, mas existe o certo e o errado instituídos sob a verdade de cada campo discursivo, o que gera a (des)cortesia a partir do horizonte que o coenunciador observa o discurso.

\section{Referências}

DELEUZE, Gilles. Foucault. São Paulo: Brasiliense, 2005.

. A dobra: Leibniz e o Barroco. Campinas, SP: Papirus, 1991. 
ECO, Umberto. A definição de arte. São Paulo: Martins Fontes, 1999.

FOUCAULT, M. A arqueologia do saber. Tradução de Luiz Felipe Baeta Neves. 8 ed. Rio de Janeiro: Forense Universitária, 2012.

GUERRA, Gregório de Matos. Outra pintura em sombras desta dama. 3 ed. Rio de Janeiro: Record, 1992.

KERBRAT-ORECCHIONI, C. Les Interactions verbales. Tomo I. Paris: Colin, 1990. . Les Interactions verbales. Tomo II. Paris: Colin, 1992. . Les Interactions verbales. Tomo III. Paris: Colin, 1994. . La conversation. Paris: Seuil, 1996.

LADRIÈRE, Jean. Vida social e destinação. São Paulo: Convívio, 1979.

MAINGUENEAU, Dominique. Gênese dos discursos. São Paulo: Parábola, 2008.

MARQUES, Maria Aldina. Quando a cortesia é agressiva. Expressão de cortesia e imagem do outro. In: OLIVEIRA, Fátima; DUARTE, Isabel Margarida. (Orgs.). Colóquio de homenagem a Fernanda Irene Fonseca. O fascínio da linguagem. Porto: Universidade do Porto. Faculdade de Letras. Centro de Linguística, 2008, p. 277-296.

NEVES, Joel. Ideias filosóficas no Barroco mineiro. São Paulo: Universidade de São Paulo, 1986.

RABELO, Manuel Pereira. Vida e morte do Doutor de Matos. v. I. Rio de Janeiro: Edição da Academia Brasileira, 1929.

RODRIGUES, David. Cortesias e descortesias duma senhora de muita treta. In: Actas do XV Encontro Nacional da Associação Portuguesa de Linguística. v. II. Braga: APL, 2000, p. 257286.

SANTA TERESA. Escritos de Teresa de Ávila. Tradução de Fabio M. Alberti. São Paulo: Loyola, 2001.

\footnotetext{
' Compreendemos gêneros do discurso na perspectiva enunciativo-discursiva, principalmente adotada por Maingueneau (2008), que articula as contrações linguísticas e situacionais e a articulação institucional de formações discursivas que remetem a uma memória de grupo.
} 


\footnotetext{
ii Maingueneau (2008) propõe o interdiscurso como primado do discurso. Afirma que um enunciado é sempre heterogêneo, ou seja, constitui-se por elementos variados e por mais que esteja topicalizado a serviço de uma instituição específica, não tem uma unidade, nem uma uniformidade, mas é múltiplo. A heterogeneidade pode apresentar-se de maneira mostrada, como no caso de enunciados que deixam explícitos a intertextualidade, ou constitutiva, em enunciados cuja referência não se associa a um discurso anterior específico, mas a formações discursivas que compõem um conjunto de discursos anteriores.
}

Recebido em 8 de março de 2018.

Aceito em 8 de maio de 2018. 